\title{
Dengue nos Países da Lusofonia: Que Ligações Epidemiológicas Poderemos Traçar?
}

\author{
Dengue Fever in Portuguese Speaking Countries: Which Epidemiological \\ Links May We Set?
}

José SILVANO ${ }^{1}$, Cândida ABREU1

Acta Med Port 2014 Jul-Aug;27(4):503-510

RESUMO

Introdução: A ocorrência recente de um conjunto de surtos de dengue em países da lusofonia previamente livres de doença, despertou-nos curiosidade quanto aos fatores concorrentes para o fenómeno e a necessidade de aprofundar conhecimentos quanto à patologia. Revemos a situação relativa à dengue nos países da lusofonia, relacionando os diferentes surtos e procurando contribuir para um melhor conhecimento do fenómeno.

Material e Métodos: Revisão da literatura relativa ao tema e informação relevante obtida de comunicações orais.

Resultados: Os surtos ocorridos entre os anos de 2009 e 2013 em Cabo Verde, Madeira e Angola (para lá da doença endémica no Brasil) partilham o mesmo vetor Aedes aegypti, mas são devidos a serotipos víricos com diferentes proveniências, como constatado em estudos genotípicos. A forte sub-notificação da doença em África e as dificuldades no diagnóstico e terapêutica são obstáculos ao real conhecimento da situação.

Discussão: A hipótese de ligação entre alguns dos surtos não está completamente afastada. Pela elevada mobilidade de pessoas entre estas zonas e pelas alterações climáticas em curso, o território de Portugal expõe-se ao risco de introdução de dengue. A luta principal, a despeito de ferramentas emergentes ainda utópicas, é sem dúvida o controlo vetorial.

Conclusão: Não foi possível provar qualquer ligação entre os diferentes surtos, mas é necessária preparação local dos profissionais de saúde, bem como o estabelecimento de estratégias de saúde pública e manutenção de redes de vigilância. Mais estudos epidemiológicos e entomológicos são necessários para caracterizar a verdadeira incidência de doença nos países lusófonos.

Palavras-chave: Dengue; Vírus da Dengue; Africa; Brasil; Portugal; Angola; Cabo Verde.

\section{ABSTRACT}

Introduction: The recent occurrence of a number of outbreaks of dengue Portuguese speaking countries with no previous disease, aroused curiosity about the competing factors for the phenomenon and a need for better knowledge of the pathology. We review the dengue-related situation in Portuguese speaking countries, linking the various outbreaks and trying to contribute to a better understanding of the phenomenon.

Material and Methods: Review of the literature on the topic and relevant information obtained from oral communications were included. Results: The outbreaks occurred between the years of 2009 and 2013 in Cabo Verde, Madeira and Angola (excluding the endemic phenomenon in Brazil), share the same vector Aedes aegypti, but are due to different viral serotypes, as shown by genotypic studies. The strong sub-notification of the disease in Africa and lack of diagnostic tools prevent a true characterization of the situation.

Discussion: The hypothesis of a link between some of the outbreaks is not completely rejected. The Portuguese territory could be exposed to an increasingly high risk of dengue introduction, not only because of the proximity with these territories, but also because of the current climate changes. The main fight is, in spite of the yet utopic emergent tools, the vector control.

Conclusion: A link between the outbreaks has not been proven but local preparation of healthcare professionals, creation of public health strategies and maintenance of surveillance systems are needed. More epidemiological and entomological studies are needed to characterize the real incidence of disease in Portuguese speaking countries.

Keywords: Dengue; Dengue Virus; Brazil; Portugal; Angola; Cape Verde.

\section{INTRODUÇÃO}

$\mathrm{O}$ aparecimento recente de um conjunto de surtos de dengue em territórios da lusofonia, num hiato temporal relativamente curto, é um fenómeno que nos parece merecer análise.

O vírus dengue foi introduzido em Cabo Verde ${ }^{1}$ (surtos registados em Outubro/Novembro de 2009) e na Madeira (surto registado em Outubro de 2012), representando, este último, a reintrodução do vírus na Europa. ${ }^{2}$ Sendo Angola território de endemicidade para o mesmo, não havia, contudo, registo de epidemias até Março-Abril de 2013, quando foi declarado um surto com epicentro em Luanda. ${ }^{3} \mathrm{O}$ Brasil, onde a doença é endémica, é até hoje o líder no número de casos reportados à Organização Mundial de Saúde
(OMS). ${ }^{4}$

A falta de experiência em lidar com a doença, que constitui uma novidade no panorama epidemiológico de alguns destes países, dificulta uma abordagem apropriada. A ausência de estruturas capazes de responder de forma cabal estende-se à falta de prática no controlo do vetor - a atitude profilática de eleição no combate à doença. ${ }^{5}$ Com as alterações climáticas, a urbanização, o aumento demográfico e do fluxo de pessoas verificados nas últimas décadas e a disseminação do vetor, o vírus encontra-se num processo pandémico global ${ }^{6}$ ocupando progressivamente novos territórios geográficos. ${ }^{7}$ A Europa, sobretudo as cidades mais setentrionais com elevada densidade populacional, estão

\footnotetext{
1. Serviço de Doenças Infeciosas. Departamento de Medicina. Centro Hospitalar do Porto. Faculdade de Medicina. Universidade do Porto. Porto. Portugal.
} Recebido: 20 de Março de 2014 - Aceite: 02 de Junho de 2014 | Copyright $\odot$ Ordem dos Médicos 2014 
também sob risco para o futuro. ${ }^{8}$

Confrontados com os recentes surtos em territórios da lusofonia que deram visibilidade à doença em Portugal continental, interessados pela dinâmica relacional destes epicentros de doença, alertados pelo crescente fluxo de falantes do português entre estas paragens, propomo-nos fazer uma súmula da situação tentando relacionar entre si a clínica e consequências da infeção, os vetores e tipos de vírus, os surtos, a introdução de novos serotipos do vírus, o papel de sistemas de vigilância epidemiológica e mecanismos de prevenção.

\section{MATERIAL E MÉTODOS}

Foi efetuada uma revisão da literatura recorrendo às bases de dados MedLine, da Organização Mundial de Saúde (incluindo DengueNet), EuroSurveillance, ProMED-mail posts e Centers for Disease Control and Prevention incluindo as palavras-chave em inglês 'dengue', 'emergent disease', 'Angola', 'Madeira', 'Cabo Verde' e 'Brazil' para artigos publicados entre 2005 e 2014.

Referências entendidas como relevantes em cada artigo foram selecionadas e verificadas. Resumos e comunicações orais obtidas em reuniões internacionais foram incluídos se entendidos como relevantes dos pontos de vista epidemiológico, entomológico e ou virológico. Por este método foram encontradas 49 artigos (dos quais 24 artigos de revisão), para além de nove comunicados/atualizações, uma linha de orientação e 15 documentos de consulta online de entidades responsáveis.

\section{RESULTADOS}

Vírus, clínica e terapêutica: a dengue é uma doença sistémica, autolimitada, causada pelo vírus da dengue
(DENV) - um vírus de ácido ribonucleico (ARN) da família Flaviviridae - e que se classifica em quatro serotipos (DENV-1 a 4). ${ }^{4}$ Foi recentemente descoberto um quinto serotipo (DENV-5), o primeiro em meio século. ${ }^{9}$ Este vírus foi identificado em amostras de sangue colhido em 2007, na Ásia, e parece ter semelhanças com DENV-4. ${ }^{9}$ É transmitida aos humanos pela picada do vetor - o mosquito Aedes (sobretudo A. aegypti, mas também A. albopictus) infetado -, cujas formas imaturas existem principalmente em reservatórios artificiais de água. ${ }^{6}$

A infeção manifesta-se geralmente após 3-10 dias de incubação. ${ }^{4,6} E$ de ponderar o diagnóstico em viajantes que desenvolvam febre até 14 dias após o regresso de região tropical/subtropical. ${ }^{10}$ Classicamente as formas clínicas eram divididas em febre da dengue, febre hemorrágica da dengue e síndrome de choque da dengue. A OMS propõe uma nova classificação com duas categorias: dengue (com ou sem sinais de alerta) e dengue grave, seguindo alguns critérios $^{4,11,12}$ (Fig. 1). Doentes com sinais de alerta devem ser internados em unidades de cuidados intermédios sendo transferidos para unidades de cuidados intensivos no caso de deterioração clínico-laboratorial. ${ }^{13}$

As formas assintomáticas/clinicamente frustres (a maioria) ${ }^{6}$ são, pela sintomatologia inespecífica, sub-identificadas, particularmente em contexto não-epidémico. Há três fases sintomáticas: uma fase febril inicial (febre de início súbito) incluindo cefaleias, vómitos, mialgias e artralgias; uma fase crítica, numa pequena proporção de doentes e por fim a recuperação espontânea. ${ }^{4,6,14}$

Níveis isolados de proteína $\mathrm{C}$ reativa (PCR) podem ser, nos locais onde se tenha acesso ao teste, um biomarcador útil para diferenciar doentes com baixo risco de malária e dengue em áreas onde as doenças coexistam. ${ }^{15}$ Elevações

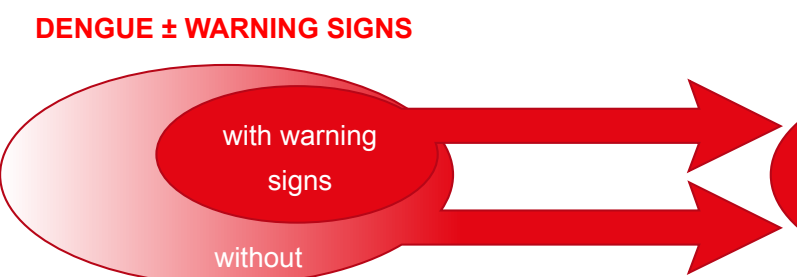

CRITERIA FOR DENGUE \pm WARNING SIGNS

\section{Probable Dengue}

Live in / travel to dengue endemic area.

Fever and two of the following criteria:

- Nause, vomiting

- Rash

- Aches and pain

- Tourniquet test positive

- Leukopenia

- Any warning sign

Laboratory-confirmed dengue

(important when no sign of plasma leakage)
Warning signs*

- Abdominal pain or tenderness

- Persistent vomiting

- Clinical fluid accumulation

- Mucosal bleed

- Leukopenia

- Lethargy, restlessness

- Liver enlargment $>2 \mathrm{~cm}$

- Laboratory: increase in HTC concurrent with rapid decrease in platelet count

*(requiring strict observation and medical intervention)
SEVERE DENGUE

1. Severe plasma leakage

2. Severe haemorrhage

3. Severe organ involvment

CRITERIA FOR SEVERE DENGUE

\section{Severe plasma leakage}

Leading to:

- Shock (DSS)

- Fluid accumulation with respiratory distress

\section{Severe bleeding \\ As evaluated by clinician}

\section{Severe organ involvment}

- Liver: AST or ALT $\geq 1000$

- CNS: Impaired consciousness

- Heart and other organs

Figura 1 - Critérios para dengue com sinais de alarme vs dengue grave - Dengue, guidelines for diagnosis, treatment, prevention and control, New edition 2009

(Reproduzido com permissão do autor de 'Dengue, guidelines for diagnosis, treatment, prevention and control New edition 2009' (Fig. 1.4, página 11 http://www.who.int/rpc/guidelines/9789241547871/en/, acesso em 25 de Setembro de 2013) 
séricas da concentração de PCR são menos comuns na dengue. ${ }^{15}$

A ausência de imunidade cruzada entre os quatro serotipos torna possível a ocorrência de infeções sequenciais. ${ }^{6}$ A resposta imune secundária em viajantes foi associada a hemorragia espontânea e outras manifestações clínicas graves, ${ }^{16}$ pelas quais o mecanismo de 'antibody-dependent enhancement ${ }^{\prime}$ será responsável. É importante informar os doentes da possibilidade de reinfeção. As crianças são mais afetadas pela forma grave de dengue (durante a fase crítica $)^{4}$ devido ao elevado título de anticorpos passivamente adquiridos por via materna,${ }^{4}$ em contexto de circulação de vários serotipos.

O tratamento é de suporte..$^{4,6}$ Fluidoterapia, repouso no leito e antipiréticos podem ser suficientes nas formas não graves. ${ }^{13,17}$ A reposição hídrica agressiva com cristaloides é determinante e inicialmente preconizada, estando as soluções colóides reservadas a casos graves. ${ }^{17}$

Dados epidemiológicos globais: a dengue é uma doença em expansão acelerada (cerca de 390 milhões de novos casos/ano estimados em 2010, quase o triplo do número avançado em 2009 pela OMS, e com tendência a aumentar), com 2,5 biliões de pessoas a viver em países endémicos, segundo diferentes dados. ${ }^{4,18} \mathrm{O}$ aumento exponencial do número de casos nas últimas décadas faz da dengue um paradigma de doença emergente (Fig. 2).

A expansão urbana verificada nas últimas décadas (as cidades com maior densidade populacional têm maior risco do que regiões rurais), ${ }^{8}$ o aumento das viagens inter- nacionais e o processo de aquecimento global são fatores justificadores da expansão da doença. ${ }^{7}$ A inexistência de medidas verdadeiramente eficazes de controlo do mosquito, permite compreender a real dimensão do problema. ${ }^{19}$

A ubiquidade do vírus nos trópicos, com a Ásia e América consideradas zonas de maior risco ${ }^{18}$ ameaça estender-se - pelo aumento de incidência nos viajantes internacionais- a áreas previamente livres de infeção. ${ }^{4} \mathrm{O}$ mapa mundial de surtos de dengue pode ser observado na Fig. 3.

O comportamento é frequentemente cíclico, com anos epidémicos e não-epidémicos e com sazonalidade ${ }^{4}$. Estas características são determinadas mutuamente por propriedades víricas, do hospedeiro e vetoriais. ${ }^{4}$

A ineficiência dos sistemas de vigilância torna os dados epidemiológicos pouco claros em África, uma região em foco neste trabalho. Contudo, é possível concluir que a doença se tem expandido, nomeadamente na região oriental do continente. ${ }^{4}$ A zona europeia é, segundo a OMS, a única onde a doença permanece não-endémica ${ }^{4}$ se excluirmos agora a Madeira.

A presença de vetores efetivos do mosquito Aedes aegypti era já uma realidade na maioria das regiões tropicais e subtropicais, mas nas últimas três décadas, uma outra variante - Aedes albopictus - vem-se disseminando a partir da Ásia, para a África, América e Europa. Uma possível justificação é a expansão do mercado internacional de pneus, propiciando a acumulação de água onde os ovos do mosquito são depositados. ${ }^{20}$ Não foi provada todavia, para este vetor, uma maior competência ou preferência pelo hospedeiro relativamente a outros, e não foi esta a

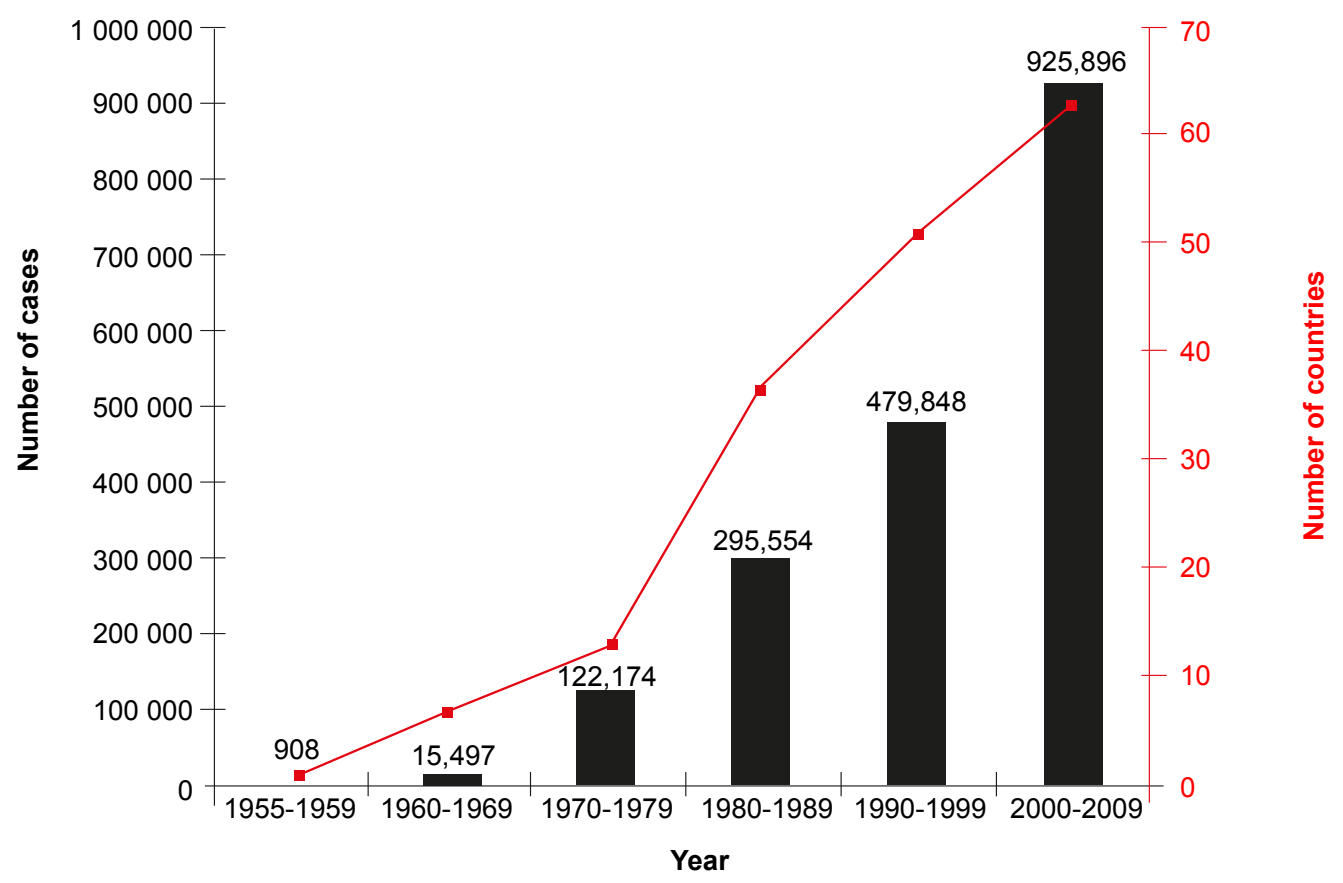

Figura 2 - Número médio anual de casos de dengue/dengue hemorrágico comunicados à OMS, e de países que comunicaram a dengue (1955-2007) - Dengue, guidelines for diagnosis, treatment, prevention and control, New edition 2009

(Reproduzido com permissão do autor de 'Dengue, guidelines for diagnosis, treatment, prevention and control new edition 2009' (Fig. 1.2, página 4 http://www.who.int/rpc/guidelines/9789241547871/en/, acesso em 25 de Setembro de 2013) 


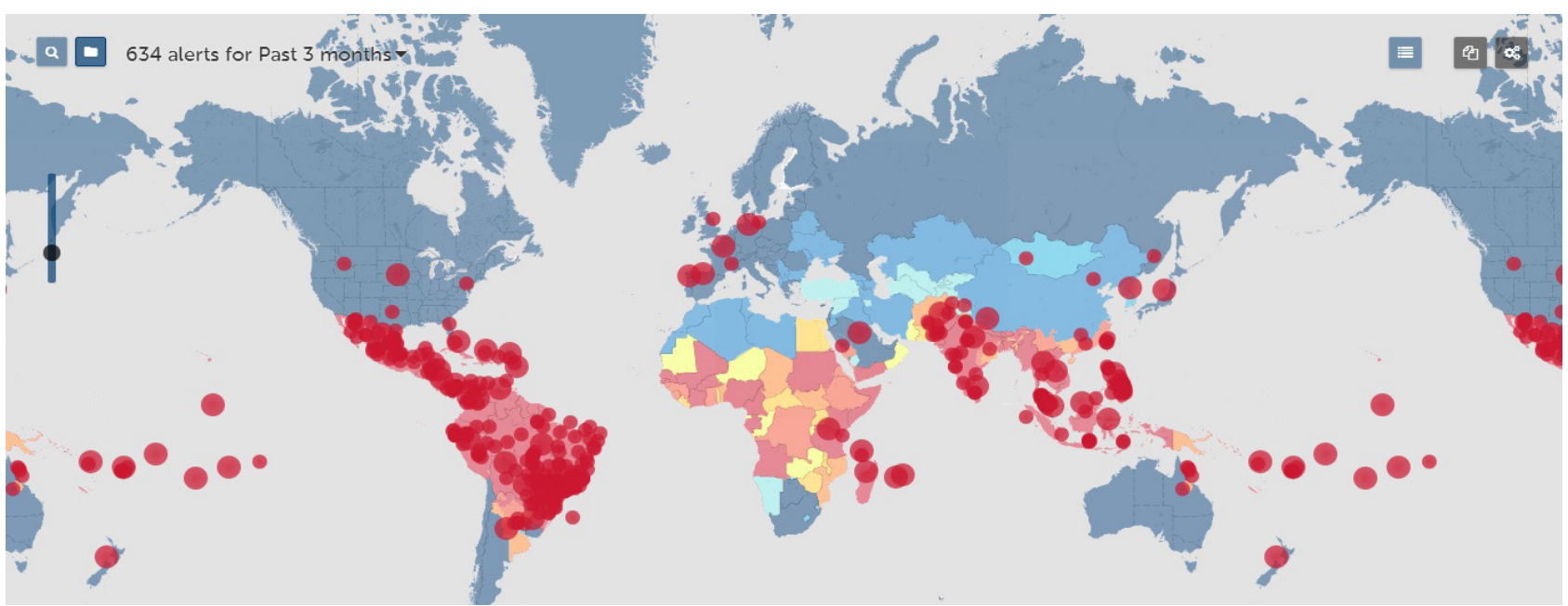

Figura 3 - Mapa de distribuição mundial dos surtos de dengue (fonte: http://www.healthmap.org/dengue/index.php, em 05/03/2014)

espécie envolvida nos surtos acima referidos..$^{20}$ No entanto, com a sua propagação, aumentamos tanto a quantidade de vetor disponível para transmitir a doença, como o território geográfico sob a sua influência.

Algumas características do vetor ajudam a compreender a epidemiologia. As fêmeas de Aedes aegypti alimentam-se sobretudo de sangue humano, colocando os seus ovos preferencialmente em reservatórios encontrados perto, ou mesmo no interior das suas casas (tais como vasos, pneus usados ou outros contentores artificiais). ${ }^{21,22} \mathrm{~A}$ picada é diurna. ${ }^{23}$ Esta relação estreita entre Aedes aegypti e os humanos no seu ambiente doméstico, permite a persistência da espécie em áreas onde os fatores climáticos per se, o não justificariam. ${ }^{24} \mathrm{~A}$ transmissão vertical trans-ovárica do vírus contamina os ovos, que são resistentes a grandes variações de temperatura, ${ }^{22}$ perpetuando o vírus dentro do próprio vetor. Isto permite manter/alargar o seu reservatório independentemente da picada em humanos. ${ }^{22,25}$

Dados epidemiológicos no Brasil: o Brasil, líder mundial no risco de ocorrência de dengue e no número de casos $\left(61 \%\right.$ do total mundial entre 2000 e $\left.2005^{26}\right)$, é o quinto país que mais casos exporta para a Europa. ${ }^{27}$ Este é o país lusófono com maior número de surtos (cerca de 4.500.000 casos registados entre 1981 e 2007) e onde a doença é endémica há mais tempo, tendo-se tornado novamente um problema significativo de saúde pública desde a reintrodução do serotipo DENV-1 em 1986 no Rio de Janeiro ${ }^{26}$. Também aí, em 1990, foi introduzido o serotipo DENV-2. A introdução de DENV-3 em 2002 (que se disseminou com grande facilidade, ganhando território aos serotipos 1 e 2) aumentou drasticamente o número de casos febris e com manifestações hemorrágicas - ainda assim em menor proporção do que o que acontece no continente asiático. A circulação simultânea dos serotipos DENV-1, DENV-2 e DENV-3 constitui um risco acrescido para o desenvolvimento de dengue grave. Ao contrário da região asiática, onde a dengue é essencialmente uma doença das crianças, no Brasil é mais incidente em adultos. ${ }^{26}$ Todavia, no primeiro semestre de 2007 verificou-se uma tendência de aumento da ocorrência de casos em crianças (< 15 anos), um padrão que se confirmou no surto de 2008 no Rio de Janeiro. ${ }^{26}$ Com a perspetiva da introdução de DENV-4 a somar aos outros serotipos num futuro próximo, a expectativa é de que novas grandes epidemias continuem a surgir.

Dados epidemiológicos na Madeira: a documentação da presença de Aedes aegypti na ilha da Madeira (uma ilha portuguesa, mas na latitude da costa norte-africana) pela primeira vez em 2005, levou à instalação de um sistema de monitorização do vetor em $2006^{28}$ - que consistiu na redução dos locais de reprodução, tratamentos inseticidas para formas imaturas e adultas, e educação pública com vista à proteção individual. ${ }^{29}$ As normas internacionais para controlo do vetor foram aplicadas nos aeroportos, nomeadamente controlo da reprodução e fumigação dos aviões antes de todos os voos na ilha, e num perímetro de 400 metros em redor do aeroporto, assim como nos portos marítimos. ${ }^{29}$ Apesar das medidas tomadas, o Aedes aegypti tornou-se a espécie mais abundante na ilha. ${ }^{30}$

A identificação de casos autóctones de dengue a partir de Setembro de $2012^{31}$ (com alerta a partir de 3 de Outubro) e subsequente identificação do serotipo vírico DENV-1 em amostras humanas marcou o início do surto. ${ }^{2}$

Foram identificados 2187 casos prováveis - 1084 foram confirmados laboratorialmente. ${ }^{31}$ A maioria apresentou febre e poucos cursaram com hemorragias. ${ }^{30}$ Nenhum dos casos reportados foi de dengue grave e nenhum óbito foi registado (o que pode ser explicado pelo facto do serotipo DENV-1 causar doença menos severa que os serotipos 2 ou 3). ${ }^{4}$ Todas as doações de sangue/órgãos foram suspensas na Madeira durante este surto. ${ }^{32}$

O estudo genotípico do vírus sugeriu um serotipo com origem sul-americana. ${ }^{33}$ Para lá dos humanos virémicos, os ovos de Aedes aegypti conseguem resistir à dessecação durante vários meses, eclodindo após o contacto com a água em apenas poucos minutos ${ }^{22,25}$ o que lhes permite deslocarem-se em contentores marítimos/aéreos. 
A abundante vegetação tropical, áreas densamente povoadas e clima adequado constituem, na Madeira, o habitat ideal para o vetor. ${ }^{28}$ A elevada densidade do mosquito, múltiplos locais para sua reprodução e falta de imunidade da população podem explicar a dimensão do surto. ${ }^{30}$ Foi sugerida uma associação temporal entre a exposição à chuva no final de 2012 e o risco de doença aumentado nos turistas expostos. ${ }^{34} \mathrm{O}$ ano de 2012 foi excecionalmente quente e húmido, um possível fator adjuvante (Reis AP, comunicação oral IHMT). Depois do início do surto, a rede de vigilância foi reforçada com campanhas de proteção pessoal e eliminação dos locais de reprodução do vetor (Reis AP, comunicação oral IHMT). Foi ainda dada formação aos profissionais de saúde e informação aos viajantes para a ilha. ${ }^{31,32}$

Não foi até ao momento demonstrada a transmissão vertical do vírus entre os mosquitos da Madeira, o que é coerente com a cessação do surto (Reis AP, comunicação pessoal). Nenhum caso autóctone foi identificado desde $03 / 03 / 2013$. Não se verificou novo surto até hoje, ainda que o vetor não tenha sido erradicado. O Aedes aegypti não foi ainda detetado na outra ilha do arquipélago, Porto Santo. ${ }^{2,35}$ É importante que casos futuros sejam alvo de serotipagem, devido ao risco de infeção heteróloga. ${ }^{30} \mathrm{~A}$ Madeira é foco de preocupação a nível europeu, pois o grande número de viajantes para este destino turístico levou à exportação de casos para outros países, como a Finlândia, Alemanha, Reino Unido ${ }^{34,36}$ (e Portugal continental). Treze países reportaram um total de 82 casos a partir da Madeira. ${ }^{34}$

Dados epidemiológicos no continente Africano: o risco calculado de dengue em África foi recentemente estimado como sendo muito superior ao anteriormente previsto - o número de infeções aparentes em África, em 2010, foi equivalente àquele da América (16 milhões vs 13 miIhões). ${ }^{18}$ A sobreposição com outras doenças infeciosas no continente e a escassa comunicação da doença concorrem para tornar este número menos surpreendente..$^{18}$ Elevados níveis de precipitação e uma temperatura adequada para a transmissão da dengue foram considerados fatores de risco elevado. ${ }^{18} \mathrm{~A}$ proximidade a centros urbanos de nível socioeconómico baixo também aumenta o risco. ${ }^{18} \mathrm{~A}$ elevada densidade populacional apresenta forte correlação com a ocorrência de epidemias - mas as variáveis térmicas e da precipitação têm mais peso em África em termos relativos. ${ }^{8}$

Dados epidemiológicos em Cabo Verde: em Cabo Verde, o primeiro surto ocorreu entre Setembro e Dezembro de 2009, causando a maior epidemia de sempre até então na África Ocidental ${ }^{37}$, com a identificação do serotipo DENV-3 como causador. A grande dimensão atingida pelo surto - 21382 casos suspeitos e seis óbitos foram registados em pelo menos cinco ilhas - Brava, Fogo, Maio, Sal e Santiago ${ }^{1,38}$ deveu-se em parte à expansão possibilitada por uma estação chuvosa particularmente vigorosa. Foi ainda confirmado mais um caso de dengue importado em 2013, algo que não se verificava no arquipélago desde
2011. ${ }^{39}$ De Janeiro a Junho de 2010, 205 casos foram registados, sendo os concelhos de Cidade da Praia e São Filipe os mais afetados. ${ }^{39}$ Durante o surto, o Ministério da Saúde de Cabo Verde, o Operational Nucleus of Information Society (NOSi) e a OMS, lançaram um sistema de alerta e comunicação de casos a nível nacional através de mensagens de texto e da Internet, fornecendo informação em tempo real a especialistas e a indivíduos em risco..$^{40} \mathrm{~A}$ OMS proporcionou também equipamento de proteção pessoal, larvicidas, máquinas para fumigação, testes diagnósticos e recomendações em língua portuguesa. ${ }^{38}$ Cabo Verde conta ainda com estratégias de controlo para mosquitos adultos e larvas (mecânico, físico e mesmo biológico com peixes da espécie gambusea e outras espécies). ${ }^{37}$

A disseminação deste serotipo - cuja transmissão no continente foi documentada pela primeira vez durante uma epidemia em Pemba, Moçambique, entre 1984 e $1985^{41}$. a partir do subcontinente Indiano para África foi ventilada como hipótese para a origem do surto em Cabo Verde. ${ }^{42}$

Dados epidemiológicos em Angola: casos de dengue de importação a partir de Angola haviam já sido identificados no INSA entre Fevereiro e Maio de 2013, dando conta da circulação da doença no país.. ${ }^{43}$ Análises das sequências do genoma viral sugeriram DENV-1 (de provável origem africano-asiática) como agente etiológico do surto em Angola. ${ }^{43} \mathrm{Um}$ grande surto de novo, com epicentro em Luanda, foi registado a partir de Abril de 2013, algo que já não acontecia há anos. ${ }^{3}$ Por volta de Janeiro, o número de casos febris agudos 'não-malária' começou a aumentar, até que o primeiro caso de dengue foi identificado a 1 de Março. ${ }^{3}$ Até ao final de Maio de 2013, apenas 527 casos suspeitos e 313 confirmados por teste rápido foram reportados, embora se calcule que os verdadeiros números sejam muito maiores. Cerca de $60 \%$ eram homens, a mediana de idades foi de 25 anos e um dos casos teve manifestações hemorrágicas significativas (Agostinho $\mathrm{MH}$, comunicação oral, IHMT).

Admite-se uma subnotificação marcada, dada a minoria de unidades de saúde a notificar casos e a baixa percentagem de acesso aos cuidados de saúde (Agostinho $\mathrm{MH}$, comunicação oral, IHMT). Todos os casos notificados eram provenientes da Província de Luanda, exceto dois da Província de Malanje. O Aedes aegypti é o único vetor de dengue em Angola, presente em todas as suas 18 Províncias, exceto Moxico. ${ }^{3}$ Em 865 casas avaliadas, 385 tinham pelo menos um contentor com larvas do mosquito (sobretudo aegypti), sendo a maioria reservatórios de água a descoberto. ${ }^{3}$ Foram tomadas medidas de saúde pública, tendo sido propostas fumigação e tratamento de habitats com Bacillus thuringiensis israelensis. ${ }^{3}$ Uma elevada proporção dos residentes de Luanda encontra-se em zonas densamente povoadas e com condições precárias de habitabilidade, o que favorece o vetor. ${ }^{3}$

Dada a prevalência elevada de malária e a ausência de testes rápidos para dengue como rotina, síndromes febris suspeitas de dengue têm de ser rastreados para malária. 
Os primeiros diagnósticos de dengue foram, por isso, tardios ou efetuados fora de Angola; muitos deles foram inicialmente dados como malária ou febre tifóide.

O ancestral vírico mais similar encontrado foi colhido na Nigéria em $1968 .^{3}$ Também a Índia e a América do Sul (94\% de semelhança genotípica com as estirpes locais) são origens plausíveis - o Brasil é o país, daqueles onde a dengue é endémica, do qual Angola mais viajantes e cooperantes recebe. ${ }^{44}$ Casos provenientes de Angola foram já relatados em quatro continentes. ${ }^{45} \mathrm{~A}$ identificação serológica/virológica das estirpes que causam estes surtos é feita sobretudo através de viajantes europeus que regressam ao seu país. Foram detetados doentes infetados com dengue procedentes de Angola no passado em 1986 e no período 1999-2002. ${ }^{46}$ É possível o ressurgimento da doença aquando de futuras épocas das chuvas.

\section{DISCUSSÃO}

Interligação entre os diferentes focos: o estreito contacto entre cada um destes países e o facto de todos os serotipos envolvidos circularem no Brasil, levam à necessidade de exclusão desse país como foco dos mesmos. Em Cabo Verde (DENV-3), foi sugerida a origem endémica, por intermédio de um vírus originário do subcontinente Indiano. ${ }^{42}$

O vírus da Madeira possui fortes semelhanças genotípicas com o que circula na América Latina, nomeadamente Colômbia, Venezuela ou norte do Brasil. ${ }^{30}$ Brasil e Venezuela tiveram de longe os maiores índices de importação de dengue (índice que leva em conta o volume de viagens e a incidência de dengue no país de origem) para a Madeira em 2012. ${ }^{47}$ Sabendo que os quatro serotipos circulam na América do Sul, ${ }^{4}$ é de admitir, por mecanismos análogos, a introdução de novos serotipos na Madeira no futuro.

Dados de sequenciação genotípica apontam para que o surto angolano tenha origem mais provável numa estirpe endémica (DENV-1, genótipo V) que circula na África Ocidental desde pelo menos 1968..$^{3,44}$ Apesar disso, uma possível ligação com o Brasil não está completamente excluída. ${ }^{44}$ Uma ligação entre os surtos de Angola e Madeira (93,6 \% de semelhança genotípica) é dada como pouco provável, não obstante a proximidade espacial e temporal entre os surtos nos dois países. ${ }^{44}$ Ainda assim, a ligação entre os mesmos não seria novidade, com a identificação em Maio de 2013, na Madeira, de dois casos importados de Angola. A mais provável das hipóteses parece ser, todavia, a da endemicidade da dengue no país. ${ }^{3}$ Portugal e África do Sul estão sob elevado risco de importação da doença no futuro, dado o volume de tráfego aéreo com os dois países. $^{44}$

Risco de introdução em Portugal continental: Brasil, Cabo Verde e Angola encontram-se entre os cinco países com maior número de imigrantes residentes em Portugal, com o consequente fluxo de pessoas e bens entre estes territórios. ${ }^{48}$

A possível introdução de espécies exóticas, como $A e-$ des albopictus (ou outras espécies de Aedes que ganhem competência) é fator de preocupação. ${ }^{23,49} A$ despeito de uma possível menor eficiência relativamente ao Aedes aegypti, não é de menosprezar a capacidade dos arbovírus, enquanto classe, de rapidamente mudarem o seu hospedeiro preferencial. ${ }^{20} \mathrm{O}$ Aedes albopictus foi já identificado em países europeus, incluindo Espanha. ${ }^{20} \mathrm{O}$ risco de dispersão geográfica do próprio Aedes aegypti para climas favoráveis ao seu estabelecimento - Portugal continental (onde foi detetado pela última vez em 1956) ${ }^{22}$ e restante sul da Europa incluídos - é real. ${ }^{22,29,44} \mathrm{O}$ movimento de humanos virémicos para zonas onde haja vetores disponíveis, é um fator crítico nos surtos, pois o mosquito raramente se desloca mais de 100 metros, alimentando-se quase exclusivamente de sangue humano. ${ }^{23,50}$ "Epidemias em grandes cidades de "solo virgem"' são frequentemente explosivas. ${ }^{23}$

Alguns casos chegaram a Portugal continental a partir de Angola e Madeira. Segundo a Direção-Geral da Saúde e o Instituto Nacional de Saúde Doutor Ricardo Jorge (INSA), desde o início de 2013 foram declarados 79 casos provenientes de Angola e cinco do Brasil, Tailândia e Indonésia. ${ }^{51}$ Cerca de $86 \%$ dos casos exportados por Angola no último surto, foram registados em Portugal. ${ }^{44}$ Em Portugal continental foram já detetados 152 casos (uma parte significativa emigrantes expatriados), segundo dados não publicados referentes ao Porto, Lisboa e Coimbra (Abreu C, comunicação oral IHMT).

Medidas de controlo: as medidas de controlo dos vetores Aedes aegypti ou Aedes albopictus são as mais efetivas de que hoje dispomos para limitar a incidência da doença..$^{4-6}$

Durante a fase febril em zona de endémica o doente deve ficar isolado num quarto, ou com rede mosquiteira, para que novos mosquitos não se infetem e tornem vetores da doença. ${ }^{4} \mathrm{O}$ registo da densidade do vetor, capacidade de transmissão e incidência da doença, aliados à adoção de sistemas de vigilância (respondendo a flutuações da população) serão o grande desafio nos países desfavorecidos em risco. ${ }^{50}$ É necessário conhecer a dinâmica do vetor (abundância, comportamento e genética) para alocar os escassos recursos. O seu uso custo-efetivo não implica erradicar o vetor, mas manter as populações sob limiares mínimos necessários à transmissão - mais do que reduzir o contacto com humanos. ${ }^{50}$

A prevenção pode ser individual ou na comunidade. A primeira passa pelo uso de redes mosquiteiras, repelentes de insetos (dietiltoluamida - DEET - na pele ou inseticidas residuais de longa duração como os piretróides - permetrina) e comportamentos básicos de proteção - vestuário adequado e evitar exposição nas horas em que o mosquito é mais ativo. ${ }^{4} \mathrm{O}$ uso de inseticidas têm a possibilidade de aumentar as resistências do vetor, podendo traduzir-se em surtos epidémicos de maior magnitude no futuro. ${ }^{52}$ Aqui, os adulticidas parecem ser mais custo-efetivos que os larvicidas. ${ }^{52}$ A segunda, pela secagem de criadouros - reservatórios de água e plantas, ou aqueles que acumulem água 
da chuva, como pneus usados. Também a canalização da água, quando possível, é importante para eliminar o vetor. ${ }^{4}$ A água estagnada é bom meio para as fêmeas de Aedes spp depositarem os ovos. ${ }^{22}$ Isto é importante porque o vetor constitui aglomerados perto das casas, possivelmente pela sua curta distância de voo e propensão a picar os humanos com elevada frequência. ${ }^{50}$

Novas abordagens procuram fazer do próprio vetor um veículo para combater a doença. A libertação de machos geneticamente modificados com capacidade para esterilizar as fêmeas é uma delas, reduzindo a carga de vetor disponível. ${ }^{6}$ A introdução da bactéria Wolbachia pipientis em embriões de Aedes aegypti gera vetores com imunidade aumentada à infeção pelo vírus da dengue ${ }^{5,6}$ - espera-se que esta resistência à infeção entre a população selvagem.

A inexistência de um modelo animal adequado contribui para uma vacina efetiva não esteja ainda disponível. Algumas encontram-se em fase experimental. A ChimeriVax (Sanofi Pasteur) - vacina atenuada tetravalente o que obsta à reinfeção por outros serotipos, baseada na produção da vacina da febre-amarela (17D) - em fase de estudo II, é a principal candidata neste momento. ${ }^{53} \mathrm{O}$ custo e eficácia de uma nova vacina não têm resposta no curto prazo - a acessibilidade deverá ser um problema nos países desfavorecidos, por sinal alguns dos mais afetados. Reforços nos meios de diagnóstico e a atualização dos profissionais de saúde são de interesse cada vez mais global, se atendermos ao fenómeno da dengue de importação.

\section{REFERÊNCIAS}

1. Communicable disease threats report. ECDC. 2013.

2. Sousa CA, Clairouin M, Seixas G, Viveiros B, Novo MT, Silva AC, et al. Ongoing outbreak of dengue type 1 in the Autonomous Region of Madeira, Portugal: preliminary report. Euro Surveill. 2012.

3. Centers for Disease Control and Prevention. Ongoing dengue epidemic - Angola, June 2013. Morb Mortal Wkly Rep. 2013;62:504-7.

4. World Health Organization. Dengue: guidelines for diagnosis, treatment, prevention and control. Geneva: WHO; 2009.

5. Vazquez-Prokopec GM. Dengue control: the challenge ahead. Future Microbiol. 2011;6:251-3.

6. Simmons C, Farrar J, Vinh Chau N, Wills B. Dengue. N Engl J Med. 2012;366:1423-32.

7. McMichael A. Globalization, climate change, and human health. N Engl J Med. 2013;368:1335-43.

8. Rogers D, Suk J, Semenza J. Using global maps to predict the risk of dengue in Europe. Acta Trop. 2014;129:1-14.

9. Normile D. Tropical medicine. Surprising new dengue virus throws a spanner in disease control efforts. Science. 2013;342:415.

10. Schwartz E, Weld LH, Wilder-Smith A, von Sonnenburg F, Keystone JS, Kain KC, et al. Seasonality, annual trends, and characteristics of dengue in ill returned travelers, 1997-2006. Emerg Infect Dis. 2008;14:1081-8.

11. Alexander N, Balmaseda A, Coelho I, Dimaano E, Hien T, Hung N, et al. Multicentre prospective study on dengue classification in four Southeast Asian and three Latin American countries. Trop Med Int Health. 2011;16:936-48.

12. Deen J, Harris E, Wills B, Balmaseda A, Hammond S, Rocha C, et al. The WHO dengue classification and case definitions: time for a reassessment. Lancet. 2006;368:170-3.

13. Verdeal J, Filho R, Vanzilotta C, Macedo G, Bozza F, Toscano L, et al. Recomendações para o manejo de pacientes com formas graves de dengue. Rev Bras Ter Intensiva. 2011;23:125-33.

14. Tang KF, Ooi EE. Diagnosis of dengue: an update. Expert Rev Anti Infect Ther. 2012;10:895-907.

\section{CONCLUSÃO}

Ainda que não fique demonstrada qualquer ligação entre os surtos recentes nos territórios lusófonos, é cauteloso manter uma cooperação na vigilância entomológica e epidemiológica, dados os riscos futuros de exportação de vetores e serotipos, atendendo aos laços culturais entre os países. Aparte a sugerida proveniência sul-americana do Aedes aegypti na Madeira, ${ }^{54}$ não foram possíveis outras conclusões quanto a exportação de vetores. Mais estudos epidemiológicos e entomológicos são necessários.

A otimização dos sistemas de saúde, a educação dos profissionais e da população e a implementação de planos de contingência/emergência são indispensáveis nesta fase, sendo o controlo do vetor primordial nos países de menores recursos. Existe em Portugal continental a necessidade dum plano nacional de controlo/medidas de contingência a ser acionadas na hipótese do surgimento de casos endémicos.

\section{AGRADECIMENTOS}

Os autores agradecem a Jorge Atouguia a leitura crítica do manuscrito e os importantes comentários e sugestões efetuados.

\section{CONFLITO DE INTERESSES}

Não existe conflito de interesses.

\section{FONTES DE FINANCIAMENTO}

Os autores declaram que não existiu qualquer financiamento para o presente trabalho.

15. Epelboin L, Boulle C, Ouar-Epelboin S, Hanf M, Dussart P, Djossou F, et al. Discriminating malaria from dengue fever in endemic areas: clinical and biological criteria, prognostic score and utility of the C-reactive protein: a retrospective matched-pair study in French Guiana. PLoS Negl Trop Dis. 2013;7:e2420.

16. Wichmann O, Gascon J, Schunk M, Puente S, Siikamaki H, Gjørup I, et al. Severe dengue virus infection in travelers: risk factors and laboratory indicators. J Infect Dis. 2007;195:1089-96.

17. Wills B, Dung N, Loan H, Dong T. Comparison of three fluid solutions for resuscitation in dengue shock syndrome. N Engl J Med. 2005;353:87789.

18. Bhatt S, Gething P, Brady O, Messina J, Farlow A, Moyes C, et al. The global distribution and burden of dengue. Nature. 2013;496:504-7.

19. Gubler D. Dengue, urbanization and globalization: the unholy trinity of the 21(st) century. Trop Med Health. 2011;39:3-11.

20. Lambrechts L, Scott TW, Gubler DJ, Lambrechts L, Scott W, Gubler J. Consequences of the expanding global distribution of Aedes albopictus for dengue virus transmission. PLoS Negl Trop Dis. 2010;4:e6461-9.

21. Polanwat A, Scott JG, Harrington LC. Insecticide susceptibility of Aedes aegypti and Aedes albopictus across Thailand. J Med Entomol. 2005;42:821-5

22. Gouveia de Almeida AP. Os mosquitos (diptera, culicidae) e a sua importância médica em portugal - desafios para o século XXI. Acta Med Port. 2011;24:961-74.

23. Reiter P. Yellow fever and dengue: a threat to Europe? Euro Surveill. 2010;15:19509.

24. Jansen $\mathrm{C}$, Beebe N. The dengue vector Aedes aegypti: what comes next. Microbes and infection. 2010;12:272-9.

25. Denguevirus.net www.denguevirusnet.com. Life cycle of Aedes aegypti. [Consultado 2014 Jan 31]. Disponível em: http://www.denguevirusnet. com/life-cycle-of-aedes-aegypti.html.

26. Teixeira M, Costa C, Barreto F, Barreto ML. Dengue: twenty-five years since reemergence in Brazil. Cad. Saúde Pública. 2009;25:S7-18. 
27. Diseases of Environmental and Zoonotic Origin Team, ECDC. Dengue worldwide: an overview of the current situation and the implications for Europe. Euro Surveill. 2007;12:E070621.1.

28. European Centre for Disease Prevention and Control. Dengue outbreak in Madeira, Portugal, October-November 2012. Stockholm: ECDC; 2013.

29. Almeida AP, Gonçalves YM, Novo MT, Sousa CA, Melim M, Gracio AJ. Vector monitoring of Aedes aegypti in the Autonomous Region of Madeira, Portugal. Euro Surveill. 2007;12:E071115.6.

30. Alves MJ, Fernandes PL, Amaro F, Osório H, Luz T, Parreira P, et al. Clinical presentation and laboratory findings for the first autochthonous cases of dengue fever in Madeira island, Portugal, October 2012. Euro Surveill. 2013;18:pii=20398.

31. Direção-Geral de Saúde. Dengue na Ilha da Madeira - situação em 01 de setembro de 2013. Lisboa: DGS; 2013.

32. Direção Geral de Saúde - Orientação 014/2012. Casos de dengue na Regiao Autonoma da Madeira. Abordagem para casos de dengue. 2012. Lisboa: DGS; 2012

33. Instituto Ricardo Jorge insa.pt. Febre de Dengue na Madeira, diagnóstico laboratorial. 09/10/2012. [Consultado 2014 Fev 01]. Disponível em http://www.insa.pt/sites/INSA/portugues/Comlnf/Noticias/Paginas/DengueMadeiraDiaglab.aspx.

34. Frank C, Höhle M, Stark K, Lawrence J. More reasons to dread rain on vacation? Dengue fever in 42 German and United Kingdom Madeira tourists during autumn 2012. Euro Surveill. 2013;18:20446.

35. Gonçalves Y, Silva J, Biscoito M. On the presence of Aedes (Stegomyia) aegypti Linnaeus, 1762 (Insecta, Diptera, Culicidae) in the island of Madeira (Portugal). Bol Mus Mun Funchal. 2008;58:53-9.

36. Huhtamo E, Korhonen EM, Vapalahti O. Imported dengue virus serotype 1 from Madeira to Finland 2012. Euro Surveill. 2013;18:20405.

37. Gómez LF, Alves J, De Pina A, Moniz F, Miranda MA, Miquel M, et al. Projecto de Cooperação Interuniversidade PCl-2011. Bioecologia e controlo vectorial de Dengue em Cabo Verde. Ministério de Ensino Superior, Ciência e Inovação de Cabo Verde, 2013.

38. World Health Organization. Global Alert and Response. Dengue fever in Cape Verde-update 1. 2009. [Consultado 2014 Fev 02]. Disponível em http://www.who.int/csr/don/2009_11_18/en/.

39. Comunicado ProMED PORT. Cabo Verde - caso importado. 2013. [Consultado 2014 Fev 02]. Disponível em http://promedmail.chip.org/pipermail/promed-port/2013-May/001022.html.

40. World Health Organization. Global Alert and Response Dengue fever in Cape Verde (WHO GAR), Cape verde, WHO outbreaks. 2009. [Consultado 2014 Fev 02]. Disponível em http://www.who.int/csr/ don/2009 10 30a/en/.

41. Gubler DJ, Sather GE, Kuno G, Cabral JR. Dengue 3 virus transmission in Africa. Am J Trop Med Hyg. 1986;35:1280-4.

42. Franco L, Di Caro A, Carletti F, Vapalahti O, Renaudat C, Zeller H, et al. Recent expansion of dengue virus serotype 3 in West Africa. Euro Surveill. 2010;15:pii=19490.

43. Instituto Ricardo Jorge insa.pt. Diagnóstico laboratorial de casos de importação de febre de Dengue de Angola. [Consultado 2014 Fev 01] Disponivel em http://www.insa.pt/sites/INSA/Portugues/Comlnf/Noticias/Paginas/DengueAngola.aspx.

44. Sessions O, Khan K, Hou Y, Meltzer E, Quam M, Schwartz E, et al. Exploring the origin and potential for spread of the 2013 dengue outbreak in Luanda, Angola. Glob Health Action. 2013;6:21822.

45. Schwartz E, Meltzer E, Mendelson M, Tooke A, Steiner F, Gautret P, et al. Detection on four continents of dengue fever cases related to an ongoing outbreak in Luanda, Angola, March to May 2013. Euro Surveill. 2013;18:pii=20488

46. Amarasinghe A, Kuritsky JN, Letson GW, Margolis HS. Dengue virus infection in Africa. Emerg Infect Dis. 2011;17:1349-54.

47. Wilder-Smith A, Quam M, Sessions O, Rocklov J, Liu-Helmersson J, Franco L, et al. The 2012 dengue outbreak in Madeira: exploring the origins. Euro Surveill. 2014;19:20718.

48. SEF/Gabinete de Estudos, Planeamento e Formação. Relatório de Imigração, Fronteiras e Asilo - 2012. Lisboa: SEF; 2013.

49. Straetemans $M$. Vector - related risk mapping of the introduction and establishment of Aedes albopictus in Europe. Euro Surveill Rapid Communications. 2008;8:1-3.

50. Scott T, Morrison A. Vector dynamics and transmission of dengue virus: implications for dengue surveillance and prevention strategies: vector dynamics and dengue prevention. Curr Top Microbiol Immunol. 2010;338:115-20.

51. Direção Geral de Saúde - Comunicado C57.01.v1. Casos de febre de dengue em Portugal. 2013.

52. Luz PM, Vanni T, Medlock J, Paltiel AD, Galvani A. Dengue vector control strategies in an urban setting: an economic modelling assessment. Lancet. 2011;377:1673-80.

53. Lang, J. Development of Sanofi Pasteur tetravalent dengue vaccine. Rev Inst Med Trop Sao Paulo. 2012;54:S15-7.

54. Seixas G, Salgueiro P, Silva A, Campos M, Spenassatto C, Reyes-Lugo $M$, et al. Aedes aegypti on Madeira Island (Portugal): genetic variation of a recently introduced dengue vector. Mem. Inst. Oswaldo Cruz. 2013;108:S3-10. 


\section{Dengue nos Países da Lusofonia: Que Ligações Epidemiológicas Poderemos Traçar? \\ Acta Med Port 2014:27:503-510}

Publicado pela Acta Médica Portuguesa, a Revista Científica da Ordem dos Médicos

Av. Almirante Gago Coutinho, 151

1749-084 Lisboa, Portugal.

Tel: +351218428 215

E-mail: submissao@actamedicaportuguesa.com

www.actamedicaportuguesa.com

ISSN:0870-399X | e-ISSN: 1646-0758

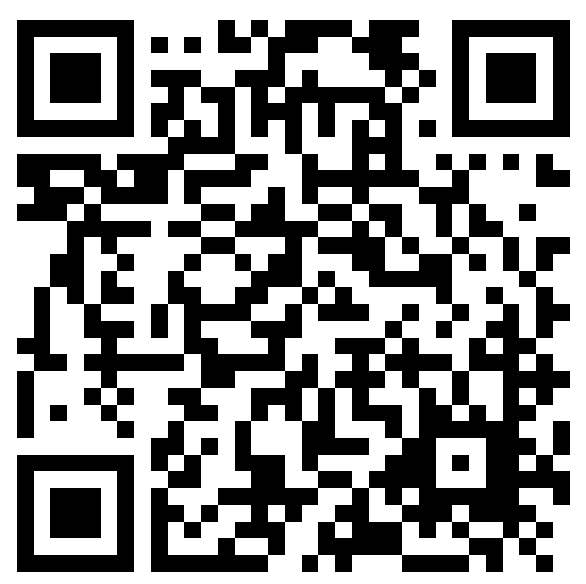

